\title{
A ética como fator de suporte ao discurso da sustentabilidade nas organizações
}

The ethics as supporting factor for

sustainability discourse of organizations

La ética como factor de soporte para el discurso

de la sostenibilidad en las organizaciones

\section{Ana Maria Dantas de Maio}

- Doutoranda em Comunicação Social na Universidade Metodista de São Paulo (Umesp)

- Mestre em Comunicação pela Universidade Estadual Paulista (Unesp), de Bauru (SP)

- Formada em Jornalismo pela Universidade Estadual de Londrina (UEL)

- Jornalista da Embrapa Pantanal, em Corumbá (MS),

- Foi docente das Faculdades Adamantinenses Integradas (FAl), em Adamantina (SP)

- Atuou em comunicação organizacional e em jornais do interior paulista por catorze anos

- E-mail:anamaio@uol.com.br

\section{Marcelo da Silva}

- Doutorando em Comunicação Social na Universidade Metodista de São Paulo (Umesp)

- Mestre em Comunicação Midiática e graduado em Relações Públicas pela Universidade Estadual Paulista (Unesp), de Bauru (SP)

- Professor e coordenador do curso de Relações Públicas da Universidade Sagrado Coração (USC), de Bauru (SP)

- Tem escrito sobre comunicação organizacional, relações públicas, discurso e estereotipia, ética e estética

- E-mail:marcelosilva_rp@hotmail.com 


\section{Resumo}

O objetivo deste artigo é estimular a discussão sobre o papel da ética na comunicação organizacional como mecanismo para conjugara construção de discursos e ouso do termo "sustentabilidade". Esta palavratem sidoaplicada de formaindiscriminada por algumas organizações para seduzir e causar impacto. A concepção de ética se ajustou à contemporaneidade; 0 mundo dos negócios hoje acata a "ética do meio-termo" - preconizada por Gilles Lipovetsky -, que propõe o afastamento dos radicalismos e se torna compatível com a ideia de sustentabilidade produzida em diferentes modalizações discursivas.

PALAVRAS-CHAVE: COMUNICAÇÃOO ORGANIZACIONAL・ÉTICA •SUSTENTABILIDADE・DISCURSO ORGANIZACIONAL.

\section{Abstract}

The aim of this article is to stimulate the discussion of the role ethics plays in organizational communication as a means of reconciling the production of discourses and the use of the term 'sustainability'. This word has been indiscriminately used by some organizations to seduce and cause impact. The concept of ethics has been adapted to contemporaneity; the business world currently accepts 'midway ethics' as professed by Gilles Lipovetsky, which proposes keeping distance from extremes, and becomes compatible with the idea of sustainability made in different discursive modalizations.

KEYWORDS: ORGANIZATIONAL COMMUNICATION•ETHICS • SUSTAINABILITY • ORGANIZATIONAL DISCOURSE.

\section{Resumen}

El objetivo de este artículo es estimular el debate sobre el rol de la ética en la comunicación de las organizaciones como mecanismo para conjugar la construcción de discursos y la utilización del término "sostenibilidad". Esta palabra ha sido aplicada de forma indiscriminada por algunas organizaciones para seducir y causar impacto. La concepción de ética se ha ajustado a la contemporaneidad; el mundo de los negocios hoy practica la "ética del término-medio", preconizada por Gilles Lipovetsky, que propone un aislamiento de los radicalismos y se vuelve compatible con la idea de sostenibilidad producida en distintas modalidades discursivas. 
A utilização indiscriminada que algumas organizações vêm fazendo do termo sustentabilidade e suas variantes ocorre sob a égide de ações, ao mesmo tempo, oportunas e oportunistas. Da noite para o dia, produtos e serviços tornam-se sustentáveis e certas iniciativas se autointitulam ecologicamente corretas por meio da comunicação. Embora haja exemplos de consideráveis avanços rumo à efetiva sustentabilidade no ambiente empresarial, é pouco provável que parte dessa "conscientização" reflita uma mudança de paradigma nas organizações contemporâneas. Um olhar crítico sobre as atitudes e os discursos organizacionais pode desvendar as contradições e incongruências que procuramos apontar nesse artigo.

Com o esgotamento da modernidade, segundo Kleber Markus (2012), as transformações e mudanças da sociedade e das organizações trazem à baila a necessidade de agregação de valor a produtos, marcas e serviços, já que estes estão cada vez mais parecidos e têm sido transformados em verdadeiras commodities. Ecologia, meio ambiente, responsabilidade social e sustentabilidade são temas que surgem como grandes catalisadores no desenvolvimento de marcas, "buscando, às vezes, a qualquer custo, uma inquestionável intersecção entre a responsabilidade social, gestão ambiental, missão, visão e os valores das organizações" (Markus, 2012, p. 31).

0 objetivo deste trabalho é refletir sobre o papel da ética na comunicação organizacional como um caminho para mitigar o abismo criado entre a construção dos discursos organizacionais e a realidade concernente a algumas empresas. Não tratamos mais da ética pura, mas flexibilizada, ou mesmo da ética do meio-termo que se alinha ao próprio conceito de sustentabilidade. Na contemporaneidade, caracterizada pelo hiperindividualismo, alguns comunicadores se apresentam menos focados em sua deontologia - princípios e valores - e mais deslumbrados com as possibilidades de sucesso e ascensão profissional. A transparência, ou pelo menos a busca e o debate sobre ela, revela-se démodée.

\section{SUSTENTABILIDADE}

Incontáveis conceitos de sustentabilidade confluem para a mesma direção: a capacidade da economia ou da sociedade de se organizar para satisfazer suas necessidades sem comprometer o ambiente para as futuras gerações. Essa essência conceitual precisaria saltar da dimensão discursiva para a prática organizacional, solidificando as ações empresariais focadas nessa filosofia. 0 esvaziamento do termo sustentabilidade está estritamente relacionado ao uso abusivo que dele se faz. Um uso que busca, em alguns casos, apenas atrair holofotes para a organização ou seus representantes. Um indicativo dessa tendência é a utilização pejorativa da palavra. Renato Terra (2012, p. 24), na revista piauí', satiriza a banalização da palavra com uma frase atribuída "sem autorização" à presidente da República Dilma Rousseff: "Toda vez que ouço a palavra sustentabilidade, lembro de reforçar o laquê"2.

O desgaste do termo fica evidente também quando a organização apresenta sua missão, visão, valores, sua política de sustentabilidade e responsabilidade social aos stakeholders. Esses públicos de interesse - quando críticos - evidenciam certo descrédito no discurso organizacional. Como atuar quando há um comprometimento real entre organização e sustentabilidade? Basta mudar a posição discursiva? A relação entre empresa e sustentabilidade precisa ser exposta? Essa exposição é condição sine qua non para legitimar a organização? As ações sustentáveis são praticadas apenas em troca de possível visibilidade? Que comunicação é essa?

10 nome da revista é grafado com " $p$ " minúsculo, padrão que mantivemos neste trabalho.

2 A revista, que pratica o jornalismo literário, atinge as classes A e B e é consumida por leitores com alto nível de escolaridade: $67 \%$ têm nível superior e $23 \%$ têm pósgraduação, segundo Juliana L. de Almeida Souza e Cláudia Alice de Ligório (2012, p. 165). 
Destarte, não podemos desconsiderar determinadas construções discursivas acerca do ethos organizacional e da imagem que as organizações constroem de si. Haja vista que, de acordo com Mikhail Bakhtin (1986), ao ignorarmos a natureza dos discursos, estamos apagando a ligação entre a linguagem e a vida. Digamos, ademais, entre a ética e a estética, 0 que as organizações dizem e o que fazem, o que divulgam e o que de fato perpassa suas práticas cotidianas. Insertas na contemporaneidade, estão imersas em um caldo sociocultural-político eivado de complexidade, inconsistência, relações escusas, favorecimento, manipulação e estereótipos.

\section{METODOLOGIA}

Componentes teóricos da análise de discurso ${ }^{3}$ fundamentam metodologicamente essa reflexão sobre fatos estilizados $^{4}$ em comunicação organizacional, tais como 0 uso indiscriminado e, por vezes, indevido do termo "sustentabilidade" na composição da linguagem formal ou informal das organizações. Partimos do pressuposto de que nenhum discurso é neutro e as intencionalidades manifestam-se por meio dos enunciados - mas também das enunciações - da comunicação institucional e mercadológica. Daí debatermos acerca da necessidade de uma sólida formação no que tange aos aspectos da práxis diária da ética por parte dos profissionais desse campo, considerando o acessório e o essencial:

O acessório é a profusão das atividades e publicações mais ou menos especializadas em torno de "receitas" da comunicação e que tem muito a ver com a lógica dos vendedores do templo. 0 essencial é esta demanda de compreensão de si e da melhora das relações com o outro (Wolton, 2006, p. 112).

Assumimos posição de reconhecimento da importância da legitimação empresarial e dos esforços reais de organizações que investem, de fato, em ações alinhadas ao desenvolvimento sustentável, especialmente quando estas promoções ocorrem no silêncio discernente que envolve a responsabilidade de gestores e comunicadores. Adotamos uma postura igualmente favorável ao analisarmos situações em que as empresas necessitam expor seus projetos de sustentabilidade para estimular o engajamento de determinados públicos. Criticamos enfaticamente a atuação de gestores e comunicadores que empregam o termo "sustentabilidade" apenas com a intenção de produzir impacto em seus interlocutores. Explicitar esses posicionamentos, em nosso entendimento, é uma demonstração de vigilância epistemológica, cuidado que deve cercar todo e qualquer trabalho científico.

A revisão bibliográfica que suporta essa análise engloba as áreas de comunicação organizacional, relações públicas e estudos de discurso e linguagem. Os principais conceitos revisitados são o de sustentabilidade, o de ética e o de discurso organizacional, por meio de uma leitura crítica em relação à produção científica já formatada.

\section{UMA IDEIA, VÁRIOS CONCEITOS}

Uma das primeiras questões que colocamos é a compatibilidade entre a comunicação mercadológica, que invariavelmente estimula o consumo, e a comunicação institucional, direcionada à imagem projetada pelas organizações. As duas

\footnotetext{
3 Não vicejamos fazer uma análise linguístico-discursiva categorizada, tal como ocorre em trabalhos focados em questões axiológicas e de sentido/significado, senão de trazer à tona uma reflexão teórica acerca de certos estratagemas discursivos que têm sido utilizados pelas organizações no contexto atual, em que vale a máxima de que as palavras não foram feitas para dizer a verdade, mas para manipular e seduzir

4 Entendemos por fatos estilizados "observações repetidas em tantos contextos que são comumente aceitas como verdades empíricas e que estabelecem limites aos quais todas novas hipóteses devem se conformar" (BUSINESS DICTIONARY.COM). Tradução nossa
} 
modalidades estão intrinsecamente ligadas, pois é impossível promover a comunicação de um produto ou serviço de forma desvinculada da imagem empresarial. Segundo Wilson Bueno (2003, p. 10), "elas são como faces de uma mesma moeda, não podendo ser pensadas como fatos isolados".

A questão do consumo é complexa na sociedade contemporânea e não é nosso objetivo aqui aprofundar essa discussão. Convém apenas ponderar que as organizações podem induzir ao consumo e agir com responsabilidade, especialmente se 0 estímulo focar a prática do consumo consciente. Já o incentivo a c consumismo se distancia dos princípios de sustentabilidade, por estar associado à rápida substituição dos bens e à sensação contínua de insatisfação.

Desse modo, a comunicação mercadológica é extremamente compatível com a lógica capitalista, pois estimula as relações de troca entre produtor e consumidor. Margarida Kunsch (2003, p. 164) a define como "todas as manifestações simbólicas de um mix integrado de instrumentos de comunicação persuasiva para conquistar o consumidor e os públicosalvo estabelecidos pela área de marketing". Na mesma obra, essa autora conceitua a comunicação institucional como "a responsável direta, por meio da gestão estratégica das relações públicas, pela construção e formatação de uma imagem e identidade corporativas fortes e positivas de uma organização" (Kunsch, 2003, p. 164). Para ela, a comunicação institucional se constrói sobre a missão, visão, propósito e valores da organização, influenciando de modo político e social a realidade na qual a organização está inserta no contexto de uma sociedade de consumidores.

O uso indiscriminado pelas organizações do conceito de sustentabilidade ${ }^{5}$ que se difunde a partir de 1980, de acordo com Gilberto Montibeller-Filho (2004), pela preocupação com a preservação ambiental conjugada à melhoria das condições socioeconômicas da população em substituição à noção de ecodesenvolvimento - tem como fim agregar vantagem competitiva à imagem e/ou marca, estratégia que terá reflexos diretos na comunicação mercadológica.

Seria ingenuidade extrema esperar que as organizações passassem a refletir de forma crítica sobre os efeitos duvidosos da comunicação mercadológica nos consumidores e clientes. Porém, os comunicadores podem ponderar algumas questões e abusar da criatividade para promover uma comunicação mercadológica mais responsável. Um ponto de partida pode ser o reconhecimento dos limites éticos da comunicação organizacional - ética como cumprimento dos valores da identidade corporativa e construída na "responsabilidade social, jamais apenas por discursos alienantes" (Simões, 2001, p. 41). Também não seria perdido qualquer esforço no sentido de aprofundar o conhecimento dos comunicadores a respeito da própria definição de sustentabilidade.

Em 1994, um levantamento mostrou que havia mais de oitenta diferentes definições para o termo ${ }^{6}$. Como o conceito geralmente se baseia no tripé econômico, social e ambiental, optamos pela explicação de Rafael M. Chiaravalloti e Cláudio V. Pádua Pádua (2011, p. 21):

A palavra sustentabilidade significa interação de duas coisas: uma sustenta e outra é sustentada (...). No caso da sustentabilidade em discussão, quem sustenta é o ambiente, toda a biosfera, as fontes de recursos que existem, e quem é sustentada é a economia. Uma economia sustentável é aquela que não acaba com as fontes de recursos.

5 Conforme Montibeller (2004, p. 49), essa expressão fora utilizada primeiramente pela União Internacional pela Conservação da Natureza (IUCN, em inglês). Em francês, a expressão é "devéloppement durable", o que equivale a desenvolvimento durável.

6 Esse levantamento foi feito pelo pesquisador John Holmberg, vice-presidente da Universidade de Tecnologia Chalmers, na Suécia. Cf. Chiaravalloti e Pádua (2011, p. 20). 
Na mesma obra, os autores apontam que os conceitos são selecionados pelos pesquisadores de acordo com sua área de atuação. Assim, um cientista social, por exemplo, vai buscar uma definição que valorize "argumentos como justiça, igualdade e bem-estar humano" (Chiaravalloti; Pádua, 2011, p. 20). Mesmo que o viés escolhido seja econômico ou ambiental, é fulcral que o comunicador tenha conhecimento sobre o tema para subsidiar suas táticas e estratégias de divulgação. Na coxia de Montibeller (2004, p. 50), acreditamos que o desenvolvimento sustentável "responde às necessidades do presente sem comprometer as possibilidades das gerações futuras de satisfazer suas próprias necessidades". Essa definição coloca as organizações no centro da cena, seja pelo sistema capitalista e a sociedade de consumo, seja pelo esgotamento ambiental, de certa forma, engendrado pelas ações de algumas empresas.

Rudimar Baldissera (2011, p. 189) lembra que, "de modo geral, a sociedade não compreende a noção de sustentabilidade em sentido complexo". Essa constatação amplia a responsabilidade dos "divulgadores" do conceito. É inconcebível que, por desconhecimento ou por falha ética, a comunicação organizacional assuma o discurso empresarial vazio da sustentabilidade em situações em que ela inexiste. 0 autor defende uma ruptura radical com a lógica econômica e questiona o uso indevido do termo.

A ideia de sustentabilidade, apresentada aqui, se distancia dos seus empregos simplistas e mitificados, como os que a reduzem à ideia de sustentação econômica (ideia de as empresas se manterem atuantes no mercado e faturando), dos seus empregos para simples fins promocionais, usos retóricos (termo da moda; politicamente correto) e, também, dos empregos para referir alguma ação isolada/pontual que, de certa forma, pode até estar caracterizada por algum nível de sustentabilidade, mas é realizada apenas para conseguir visibilidade, imagem-conceito e/ou legitimidade (Baldissera, 2011, p. 189).

A prática dessa comunicação que se apropria da ideia de sustentabilidade com fins promocionais certamente não encontra eco nas organizações que, de fato, levam a sério os princípios sustentáveis. Nem sempre as iniciativas precisam ser mostradas $^{\top}$. Se a divulgação de ações sustentáveis tiver como finalidade apenas a obtenção da visibilidade e da visualidade empresarial, ela se torna dispensável. Cabe divulgação dirigida se houver necessidade de estimular a mobilização social ou o engajamento de determinados grupos afetados pelas ações. Explorar a sustentabilidade como forma de buscar apenas reconhecimento ou legitimidade revela, no mínimo, desinformação por parte de gestores e de comunicadores, já que hoje temos públicos mais resistentes aos discursos construídos sob o intento de levar uma ideia de envolvimento com as mazelas sociais e ambientais "antes mesmo de desenvolverem tais programas que comumente não saem do papel de seus viciados planejamentos estratégicos - verdadeiros jogos de guerra" (Markus, 2012, p. 34).

Vale aqui uma observação sobre a questão da visibilidade associada ao processo de legitimação social. Não há incongruência alguma no fato de as organizações buscarem legitimidade no contexto em que estão inseridas. Para Ana Thereza N. Soares e Luisa da Silva Monteiro (2012, p. 53), "o interesse por legitimação tem se tornado até mesmo uma questão de sobrevivência, pois ter legitimidade ou não está relacionado à continuidade das organizações". 0 problema se instaura quando a empresa explora indevidamente o discurso vazio da sustentabilidade para conquistar visibilidade, com a intenção de se tornar legítima. Nesse caso, a filosofia da sustentabilidade não faz parte do DNA da organização. Há uma espécie de simulação.

O chamado marketing verde das empresas também passa por um período complicado, de total descrédito. Cilene Victor (2009, p. 22) diz que, "quando sustentada apenas em discursos, a política ambiental de uma empresa restringe-se às ferramentas de marketing". No mesmo estudo, a autora apresenta a quarta edição da pesquisa nacional "O que os brasileiros pensam do

\footnotetext{
7 Entendemos que há incoerência em divulgar ações e programas de sustentabilidade pelo simples ato de divulgar, haja vista que as organizações estão simplesmente cumprindo uma obrigação; por analogia, é como um indivíduo que se orgulha de ser honesto, ou seja, cumpre uma obrigação e a alardeia a todos os rincões, como se houvesse grande mérito nisso.
} 
meio ambiente e do desenvolvimento sustentável" (Brasil, 2006), apontando que vem caindo regularmente o reconhecimento que os entrevistados têm a respeito da atuação dos empresários em prol do meio ambiente. Definitivamente, não é mais possível brincar de sustentabilidade no mundo corporativo contemporâneo, pois a proposição de que é possível produzir mais com menos guarda no seu bojo uma série de contradições, que se ancoram e apagam em certas formações discursivas acerca da sustentabilidade. É chegada a hora de falarmos sobre o equilíbrio entre a ética e a estética das organizações.

\section{ÉTICA: UMA TEORIA DA RELATIVIDADE}

Um comunicador com sólida formação no campo da ética, dos valores e da moral, estará sempre (pre)ocupado em fundamentar suas ações na verdade e na transparência. Todavia, ao longo do tempo, conceitos até então consolidados, como ética e verdade, sofreram certa flexibilização. Clóvis de Barros Filho (2003, p. 39) afirma que "a verdade é um juízo que se diz ou se escreve (é do âmbito da linguagem, da comunicação) e se interpreta. (...) Enquanto apropriação discursiva, a verdade é tendencial".

Que verdade cabe, então, ao comunicador defender? Como agir eticamente em um sistema que não permite a prática da ética pura? A ética defendida pelos códigos de conduta profissional é compatível com os desafios, os conflitos, as cobranças, o ritmo e a superexposição que caracterizam os novos ambientes organizacionais? 0 ensino da ética nos cursos de comunicação é suficiente para que o indivíduo mantenha no mercado um padrão moral mínimo? 0 profissional de comunicação organizacional se interessa em ampliar seu conhecimento e manter-se atualizado sobre ética durante os intervalos das longas jornadas de trabalho?

Nossa contribuição limita-se a considerar o entendimento que alguns estudiosos vêm manifestando a respeito do tema. Ao escrever sobre uma nova ética para uma nova era, Bernardo Kucinski $(2005$, p. 24) afirma que

cada indivíduo, nesses tempos pós-modernos, teria a faculdade de decidir sua própria conduta, cultivar seus próprios valores. É a desqualificação do direito de exigir determinados comportamentos. É o retorno também à mais primordial de todas as discussões éticas: a da possibilidade ou não de haver uma ética.

Essa observação não deixa dúvidas de que o individualismo tornou-se uma instância significativamente mais poderosa que a coletividade, principalmente quando o assunto é ética. Pouco pensamos e agimos em função da alteridade, focando mais na construção de uma identidade personalista. Esse pensamento é compartilhado por Lipovetsky (2005, p. 235), que sugere cuidado com as ilusões: "essa consciência dos limites do individualismo não restabelece, de nenhum modo, as normas adstringentes e inflexíveis de outrora. A fase que se esboça rejeita tanto o amoralismo ou a imoralidade individualista quanto o sacrifício moralista".

Desponta um cenário aparentemente crítico e apocalíptico. Se a contemporaneidade não permite a convivência da ética fundamentalista com o mundo atual dos negócios, ajusta-se o entendimento da ética para que os profissionais possam se apoiar em alguns valores, mesmo que estes representem meios-valores. Flexibilidade e capacidade de negociação são atributos não mais desejáveis, mas obrigatórios no ambiente profissional.

8 A reflexão a respeito de cada uma dessas questões mereceria um estudo à parte, que não cabe neste trabalho. Apostamos em descrevê-las apenas com o intuito de compartilhar com o leitor algumas angústias que nos interpelam. 
Estamos numa fase que recusa as soluções drásticas, à procura de uma ética do meio-termo. Sim, meio-termo entre direitos do indivíduo e obrigações dos empregados, entre interesses dos acionistas e interesses dos consumidores, entre benefícios e proteção do meio ambiente, entre rentabilidade e justiça social, entre presente e futuro. 0 ideal da business ethics é a 'justa medida', aquele difícil mas necessário equilíbrio entre os diversos interesses contraditórios dos agentes econômicos e sociais (Lipovetsky, 2005, p. 235).

Esse equilíbrio faz-se indispensável não apenas na rotina e nos planejamentos organizacionais, mas especialmente em seus discursos, na forma como a empresa se apresenta à sociedade, aos seus públicos e ao mercado. 0 dilema ético deve considerar ainda a relação custo/benefício das decisões empresariais. Para Dan Lattimore et al. (2012, p. 87), os profissionais de relações públicas "devem avaliar os benefícios em relação aos danos de suas atividades de comunicação e/ou ter a determinação moral para dizer sim ou não, porque os efeitos de longo prazo de uma má decisão irão se sobrepor aos ganhos de curto prazo".

Assim como Mayra R. Gomes (2002, p. 24), entendemos por discurso "uma unidade de conteúdo que organiza as significações em direção a um sentido, que por sua vez organiza uma concepção de mundo, de homem, de saber e de sociabilidade". No caso das organizações, o discurso pode ser formal - quando clarificado em seus princípios, como missão, visão, objetivos, memórias etc. - ou informal - quando se manifesta por meio de falas, ações, imagens, projetos, iniciativas ou outras enunciações investidas de significado e partilhadas com interlocutores.

Para a analista de discurso de tradição francesa Eni Orlandi (2007, p. 21), "as relações de linguagem são relações de sujeitos e de sentidos e seus efeitos são múltiplos e variados (...); discurso é efeito de sentidos entre interlocutores". Muito embora as organizações signifiquem por meio de sua comunicação institucional e mercadológica, o sentido, a decodificação, aceitação ou rejeição de certos discursos estão muito mais focados nas condições de interpretação dos públicos de interesse que nas intenções e "manipulações" discursivas das organizações. Essas interpretações, como já foi dito, podem criar o sentimento de resistência ou indiferença, comprometendo a intencionalidade da produção do discurso.

Por questões políticas, algumas organizações têm adotado em seus discursos o que Júlio César Barbosa (2011, p. 66) classifica como palavras-armadilha, "utilizadas de maneira aleatória, na tentativa de criar algum nível de impacto sobre o leitor, são muitas vezes sobrepostas, sem nenhuma especificação do que realmente a organização tenta passar, como mensagem, para seu público". Como exemplo, ele cita os termos "valor, oportunidades, soluções, negócios e oferecer", frequentemente presentes na descrição das missões e das visões empresariais, ou seja, no discurso formal das organizações.

Relevante problematizarmos essas formulações ideológicas que se materializam no discurso das organizações, já que comportam uma heterogeneidade eivada de aspectos físicos, sociais, psicológicos e fisiológicos. "Mas quem diz linguagem diz demarcação, significação e comunicação. Neste sentido, todas as práticas são tipos de linguagem, visto que têm a função de demarcar, de significar, de comunicar" (Kristeva, 1980, apud Gomes, 2000, p. 9).

Essa necessidade de causar impacto em determinados públicos por meio de um discurso frívolo pode estar relacionada à imaturidade da organização ou ao apagamento das antinomias sociais e organizacionais levado a efeito por determinados comunicadores, por vezes responsáveis pela produção dos discursos organizacionais formais ou informais ${ }^{9}$. Ao que tudo indica, o vocábulo sustentabilidade e seu caleidoscópio de significados também vêm sendo utilizados como palavrasarmadilha por algumas empresas, o que provoca reações adversas do público.

9 Algo que pode ocorrer de modo inconsciente, pois acreditamos que a linguagem é opaca e, muitas vezes, a enunciação opera em quadros de apagamento das contradições inerentes às organizações, deixando dúvidas no campo do dizer, entre o dito e o não dito, que leva a um movimento de significação "romantizado" e ingênuo, que olvida a possibilidade de uma percepção outra por parte dos sujeitos que compõem os distintos públicos de uma organização. 


\section{ANO 10 • NÚMERO $19 \cdot 2^{0}$ sem 2013 • ORGANICOM \\ A ÉTICA COMO FATOR DE SUPORTE AO DISCURSO \\ DA SUSTENTABILIDADE NAS ORGANIZAÇÕES}

O progresso tende a representar avanços materiais quantitativos, associados a uma melhor qualidade de vida. Mas é evidente que esta fórmula mágica de bem estar não se sustenta. 0 crescimento econômico é quase sinônimo de caos. As organizações buscam o lucro a qualquer custo e os consumidores alimentam essa fornalha que os incendiará depois (Markus, 2012, p. 39).

Importante também é relativizar o conceito de transparência. Nem tudo precisa ser mostrado ou exposto pela comunicação organizacional. Defendemos uma política de abertura e de divulgação do que for socialmente relevante. A transparência deve ocorrer também quando indagações externas questionarem princípios e práticas da organização. De acordo com Dominique Wolton (2004, p. 78),

a transparência não evita os conflitos e a informação não basta para criar conhecimentos. Há uma grande distância entre visibilidade e ação. Não somente porque as crises são imprevisíveis, apesar de todo o sistema de informação, mas, sobretudo porque permanece uma 'diferença de natureza' entre o conhecimento da realidade e a vontade ou a capacidade de modificá-la. Trata-se de duas disposições de espírito bem diferentes. Observar não é agir.

Se na contemporaneidade a verdade é tendencial, a transparência não evita conflitos e a ética pode ser questionada em sua essência, cabe ao comunicador nortear sua atuação por meio de valores compatíveis com a realidade da profissão. 0 estudo contínuo sobre o campo da ética poderá ampliar o conhecimento desse profissional a respeito das melhores condutas a seguir e das decisões mais justas a tomar, olhando sempre um horizonte mais complexo que tão somente o organizacional. Portanto, flexibilizada ou não, do meio-termo ou não, a ética mantém-se imprescindível para o exercício da profissão que lida cotidianamente com a comunicação, haja vista que a ascensão das atividades deste campo "não significa um pouco mais de óleo nas engrenagens e mais plumas e paetês, é uma necessidade absoluta" (Wolton, 2006, p. 104).

Essa comunicação, do ponto de vista da ideologia tecnicista, prioriza a velocidade e continuidade, ressaltando o papel dos sistemas de informação, no seio dos quais os homens, as sociedades e a comunicação funcionam - paradoxalmente - na descontinuidade e na convivência. Dessa maneira, a compreensão dessa dualidade, conforme assevera Wolton (2011), deve prevalecer se não quisermos "perder" a sociedade para uma falsa democracia e sustentabilidade, apregoadas por um senso comum, no nosso caso, de ética, comportamento e discurso ecosófico - de efetivas políticas de sustentabilidade e conservação ambiental.

Há um conflito de legitimidade da ética que se plasma em discursos institucionais e mercadológicos, trazendo à tona um dos maiores desafios sociais, culturais, políticos e organizacionais do futuro: por um lado, efetivas políticas institucionais de conservação ambiental e sustentabilidade (social, econômica, ecológica, espacial/geográfica e cultural); por outro, discursos de reconhecimento e legitimidade, erigidos pelas organizações em uma sociedade marcadamente tecnológica, difusa, hodierna, mas paradoxalmente, líquida, inconsistente e espetacularizada.

\section{CONSIDERAÇÕES FINAIS}

Embora o conceito de ética tenha sofrido flexibilizações recentes e conjugue entendimentos diversos, sua prática nas rotinas da comunicação organizacional torna-se cada dia mais indispensável. Ela se coloca como opção para fundamentar os discursos das organizações, especialmente em relação à sustentabilidade e ao desenvolvimento sustentável. Sabemos que esses discursos contemporâneos estão carregados de palavras-armadilha, adotadas com a intenção de criar impacto, manipular a imagem corporativa e atuar no campo da sedução, fabricando uma realidade na qual se institui uma muralha entre aspectos éticos e estéticos no ventre da comunicação. 
A ética do meio-termo, preconizada por Lipovetsky, é própria do mundo dos negócios e apresenta-se como exigência mínima para a condução da comunicação organizacional em níveis aceitáveis. Não se trata, portanto, de manter intocável o meio ambiente, mas de se obter dele benefícios até o limite que garanta sua conservação. 0 mesmo cuidado vale para outras relações, nas quais a responsabilidade da organização e do comunicador se faz incondicional.

Atuar de forma ética em comunicação organizacional é observar no planejamento estratégico - que se traduz em ações diárias - o comprometimento com a transparência e a verdade, embora esses dois valores também tenham se adaptado à interpretação hodierna. Em situações de conflito e discordância, o comunicador não pode se omitir: precisa expor os argumentos que conduzam a organização ao equilíbrio entre o discurso e as realizações. Compete à equipe de comunicação organizacional integrada avaliar a necessidade - ou não - de expor eventuais ações direcionadas à sustentabilidade e a forma mais sensata de tratar 0 assunto.

Uma atuação ética em comunicação relacionada à sustentabilidade se expressa ao menos em duas vertentes. Primeiro, o comunicador deve assumir o compromisso de fomentar na organização os princípios da sustentabilidade, estimulando a prática real de atitudes conscientes que contribuam para a conservação ambiental, para a justiça social e a viabilidade econômica. Projetos e programas que traduzam ações nesse sentido são sempre bem-vindos, desde que a concepção de sustentabilidade faça parte da visão empresarial, da personalidade da organização.

A segunda vertente diz respeito à obrigação de alertar a cúpula da organização em relação aos riscos de um discurso vazio sobre sustentabilidade. Mesmo em pequenas empresas, cabe ao profissional de comunicação orientar os dirigentes em relação ao uso de palavras-armadilha nos discursos mercadológicos e institucionais construídos. É inadmissível nos tornarmos cúmplices de certas retóricas manipulativas e reificadoras da realidade. A contemporaneidade abalou conceitos, mas não destruiu o vínculo entre ética, profissionalismo e sucesso das organizações que equilibram estética e ética na dita sociedade de consumidores: essas questões são, na verdade, um sintoma da inteligência crescente e crítica dos públicos e da necessidade de uma comunicação menos centrada em suas ferramentas, pois o discurso da sustentabilidade, parafraseando Wolton (2006), veicula valores que vão além dele próprio.

\section{REFERÊNCIAS}

BAKTHIN, Mikhail (Voloshinov, 1929). Marxismo e filosofia da linguagem. 3. ed. São Paulo: Hucitec, 1986.

BALDISSERA, Rudimar. Da responsabilidade social à sustentabilidade: comunicação, cultura e imaginários. In: FARIAS, Luiz Alberto de (Org.). Relações públicas estratégicas: técnicas, conceitos e instrumentos. São Paulo: Summus, 2011. p. 179-194.

BARBOSA, Júlio César. Princípios organizacionais: processo de construção no contexto do discurso organizacional. In: FARIAS, Luiz Alberto de (Org.). Relações públicas estratégicas: técnicas, conceitos e instrumentos. São Paulo: Summus, 2011. p. 61-77.

BARROS FILHO, Clóvis de. Ética na comunicação. 4. ed. São Paulo: Summus, 2003.

BRASIL. Ministério do Meio Ambiente; Iser-Instituto deEstudos da Religião. Oque os brasileiros pensam sobrea biodiversidade. Brasília, 2006. Disponível em: <http://www.cbd.int/doc/meetings/nbsap/nbsapcbw-sam-01/other/nbsapcbw-sam-01-brasilestudo.pdf> Acesso em: 23 nov. 2012. 
BUENO, Wilson da Costa. Comunicação empresarial: teoria e pesquisa. Barueri, SP: Manole, 2003.

BUSINESS DICTIONARY.COM. Stylized facts. Washington. Disponível em: < http://www.businessdictionary.com/definition/ stylized-facts.html>. Acesso em: 14 nov. 2013.

CHIARAVALLOTI, Rafael Morais; PÁDUA, Cláudio Valadares. Escolhas sustentáveis: discutindo biodiversidade, uso da terra, água e aquecimento global. São Paulo: Urbana, 2011.

GOMES, Mayra Rodrigues. Ética e jornalismo: uma cartografia dos valores. São Paulo: Escrituras Editora, 2002.

Jornalismo e ciências da linguagem. São Paulo: Hacker Editores; Edusp, 2000.

KUCINSKI, Bernardo. Jornalismo na era virtual: ensaios sobre o colapso da razão ética. São Paulo: Fundação Perseu Abramo; Editora Unesp, 2005.

KUNSCH, Margarida M. Krohling. Planejamento de relações públicas na comunicação integrada. 4. ed. - rev. e ampl. São Paulo: Summus, 2003.

LATTIMORE, Dan et al. Relações públicas: profissão e prática. 3. ed. Porto Alegre: AMGH, 2012.

LIPOVETSKY, Gilles. 0 casamento da ética com os negócios. In: LIPOVETSKY, Gilles. A sociedade pós-moralista: 0 crepúsculo do dever e a ética indolor dos novos tempos democráticos. Barueri, SP: Manole, 2005. p. 221-258.

MARKUS, Kleber. 0 futuro quatro horas atrás: comunicação ecosófica nas organizações. In: GALINDO, Daniel (Org.). Comunicação institucional e mercadológica: expansões conceituais e imbricações temáticas. São Bernardo do Campo, SP: Metodista, 2012.

MONTIBELLER-FILHO, Gilberto. O mito do desenvolvimento sustentável. Florianópolis: UFSC, 2004.

ORLANDI, Eni de Lourdes Puccinelli. Análise de discurso. Campinas, SP: Pontes, 2007.

SIMÕES, Roberto Porto. Relações públicas e micropolítica. São Paulo: Summus, 2001.

SOARES, Ana Thereza Nogueira; MONTEIRO, Luisa da Silva. O contexto das organizações: uma leitura sobre suas configurações e seus processos comunicacionais. In: OLIVEIRA, Ivone de Lourdes; LIMA, Fábia Pereira (Org.). Propostas conceituais para a comunicação no contexto organizacional. São Caetano do Sul, SP: Difusão; Rio de Janeiro: Senac Rio, 2012. p. 49-66.

SOUZA, Juliana Lopes de Almeida; LIGÓRIO, Claudia Alice de. Jornalismo literário: o ritual da revista piauí. Revista Brasileira de Ensino de Jornalismo, Ponta Grossa (PR), v. 1, n. 9, p. 143-172, jan-jun. 2012. Disponível em: < http://www.fnpj.org.br/rebej/ ojs/index.php/rebej/article/view/206/148>. Acesso em: 2 jun. 2012.

TERRA, Renato. Casa onde mulher manda até galo bota ovo. piauí, Rio de Janeiro, n. 70, p. 24, jul. 2012.

VICTOR, Cilene. Sustentabilidade: pauta jornalística ou marketing verde? In: VICTOR, Cilene; CALDAS, Graça; BORTOLIERO, Simone (Org.). Jornalismo científico e desenvolvimento sustentável. São Paulo: All Print, 2009. p. 15-30. 
WOLTON, Dominique. Pensar a comunicação. Brasília: Universidade de Brasília, 2004.

É preciso salvar a comunicação. São Paulo: Paulus, 2006.

Informar não é comunicar. Porto Alegre: Sulina, 2011.

Artigo recebido em 02.09.2013 e aprovado em 24.11.2013. 